\title{
Analysis on the Mechanism of Financial Support for the Development of Cultural Industry
}

\author{
Miao Tian ${ }^{1,2,3, a}$ \\ ${ }^{1}$ School of Finance, Guizhou University of Finance and \\ Economics \\ ${ }^{2}$ Guizhou Institute for Urban Economics and Development, \\ Guizhou University of Finance and Economics \\ ${ }^{3}$ Guizhou Institution for Technology Innovation \& Entreprene \\ urship Investment \\ Guiyang China \\ a893806975@qq.com
}

\author{
Mu Zhang,b,* \\ ${ }^{1}$ School of FinanceGuizhou University of Finance and \\ Economics \\ brim_007@163.com \\ Guiyang China \\ *Corresponding author
}

\begin{abstract}
In order to analyze the mechanism of financial support for the development of cultural industry and develop cultural industry better, this article firstly analyzes the characteristics of cultural industry and cultural industry financing; then analyzes the mechanism of financial support for the development of cultural industry from three aspects: financial scale, financial structure and financial efficiency; finally found that the capital is an important driving force for the development of cultural industry. The financial support is the core mechanism for this impetus to develop inner effect effectively. Under the optimal design of the capital allocation mechanism, financial support provides sustained capital support for the development of the cultural industry and promotes the development of the cultural industry through the effective mobilization and capital agglomeration.
\end{abstract}

Keywords-cultural industry, financial support, financial efficiency, financial scale, financial structure

\section{INTRODUCTION}

In recent years, as one of the fastest growing industries in China, the cultural industry attracts more and more attention because of its great potential, energy saving, environmental protection and other advantages. The development of cultural industry not only can improve the soft power of our culture but also can promote the economic and cultural transformation of china. In the sixth Plenary Session of the 17th CPC Central Committee, the CPC Central Committee has made important instructions on the reform and development of cultural industry, and clearly put forward that in 2016 the increase in the value of China's cultural industry should reach $5 \%$ of the GDP. This indicates that China will vigorously develop the cultural industry into a pillar industry of the national economy.

In the study of the mechanism of financial support for the development of cultural industry, on the one hand, domestic and foreign research literature mainly focused on the relationship between finance and industry. Goldsmith (1969) argues that there is a causal relationship between financial and economic growth caused by industrial structure changes. Goldsmith assumed a series of financial related indicators to judge the level of financial growth of a country, and he believes that the level of financial growth is higher than the growth of the real economy, but the growth of a country's financial space is not infinite: when the finance develops to a certain stage, the growth level will be stable at the certain stage[1]. Wu Haihua, Zhang Xu (2001) starting from the relationship between industrial structure, financial development and economic growth, made a comprehensive and systematic analysis of the mechanism of the financial support for the change of industrial structure and solved the problem of how to choose the mode of finance in China's industrial development. They think the process of industrial structure adjustment affected by finance is: finance $\rightarrow$ savings $\rightarrow$ investment $\rightarrow$ capital flow structure $\rightarrow$ distribution structure of production factor $\rightarrow$ capital stock structure $\rightarrow$ industrial structure, and points out that the higher the degree of financial economy, the more obvious the transfer process is[2]. Cai Hongyan, Yan Qingmin (2004), according to the relevant data of China's industrial sectors, examined the relationship between capital flow and the adjustment of industrial structure in China's capital market as well as the capital distribution of the stock market in industries of different growths. The study found that China's most economic advantaged industry did not get the effective recognition and development, at the same time, in the capital flows of low growth industry, the role of non-market government support made greater efforts in the play[3].

On the other hand, through the combined research of cultural industry and financial support in china, it can be found that the current research on the financial support for the cultural industry is still relatively small, only some of the research stays at the theoretical stage and no further research about the financial support in the development of cultural industry, and lack of exact definition and theoretical forms of many derivatives which belongs to "cultural industry and finance". Domestic financial support for cultural industry mainly focuses on the following aspects: Zhou Zhengbing (2013) analyzed the differences of financial support for cultural industry in the United States, France and China from two aspects: the policy of financial support for cultural industries and commercial financial support for cultural industry. It also puts forward that the new policy should be introduced to strengthen the financial investment and build a good financial environment for the development of the cultural industry, such as policy guarantee, 
policy investment and so on. And in terms of commercial financial support for cultural industries, China should establish a risk compensation system and a comprehensive financial intermediary service system, build a commercial finance in the cultural industry to make a good external environment[4]. Peng Zhongping (2013) studied the current situation of cultural industry financing in Guangxi Province, found that there are two main channels in financial financing of the cultural industry: indirect financing and direct financing. Indirect financing is mainly through bank loans, and direct financing is mainly through investment, joint investment or IPO financing. Studying the present situation of Guangxi Province, the cultural industry in the financial support is mainly indirect financing through bank loans to meet their demand for capital, however the direct financing to finance is rather less. Although the culture industry has a relatively large investment space, investors' willing are still not high[5]. Guo Shiping, Shi Weihua (2005) believe that currently the development of cultural industries in China lacks financial support, and the main problem is that the media assets property rights are not clear; the media steps into the group under the impetus of the government which is a product of non-market competition, may not effectively increase the effect; there is also serious regional and departmental barriers[6]. He Shuhong (2011) focuses on the study of the cultural industry in Yunnan Province, and founds that the cultural industry financing is difficult, mainly because local banks can hardly evaluate cultural enterprises, and some enterprises do not have the appropriate collateral, leading to no credit support[7]. Wang Yang (2010) focuses on the analysis of the current development of cultural industry in Shaanxi province. He believes that the government's investment, financial support, social financing, foreign investment, capital of the enterprise itself are the five source of capital in cultural industry. But there are restrictions in these aspects in Shaanxi Province. He suggested that the government should strengthen the guidance of funds, accelerate financial institutions to innovation, improve the financing system, and nurture qualified financing subject[8].

Considering the previous studies, this article analyzes the mechanism of the financial support for the development of cultural industry in financial scale, financial structure and financial efficiency which start with the characteristics of cultural industry, the characteristics of financial finance and the characteristics of cultural industry financing.

\section{DEFINITION OF CULTURAL INDUSTRY AND FINANCING CHARACTERISTICS}

\section{A. Definition of Cultural Industry}

\section{1) Definition of Cultural Industry}

The main activities of the cultural industry are the production and provision of spiritual products, aiming to meet the cultural needs of the people. Generally it refers to the creation and distribution in cultural meaning; literarily it includes artistic creation, music creation, photography, dance, industrial design and architectural design. [9]

\section{2) Classification of Cultural Industry}

Cultural industries mainly include nine categories:
- News service, mainly the news industry.

- Cultural products publishing and copyright, including publications, audio-visual materials, electronic publishing and copyright.

- The film and television broadcasting services, refers to the production and distribution of radio and television, cultural television companies and other related enterprises.

- Cultural and artistic services, mainly including: the creation of cultural performances and venues, as well as cultural protection, cultural facilities services, cultural studies and cultural community services, and other cultural and artistic services.

- Network of cultural services, namely cultural services mainly on the Internet, mainly includes four aspects: Internet news services, Internet publishing services, Internet electronic bulletin services and other Internet information services.

- The cultural services of leisure and entertainment, mainly includes entertainment culture and some tourism culture.

- Other cultural services, including the rental and sale of cultural products, advertising and exhibition of cultural products, cultural and artistic business agent services.

- The production of cultural products, cultural equipment and related cultural products.

- The sale of cultural products, cultural equipment and related cultural products.

\section{B. The Characteristics of Cultural Industries}

- The cultural industry is a kind of creative industry, which is characterized by innovative thinking. The majority of scholars at home and abroad think that cultural industry is a kind of creative industry, and the most important dynamic characteristic is its innovation and creativity. The industrialization of culture is the essential characteristic of the cultural industry, and it is necessary to use new ideas, new views and new methods to create wealth.

- Cultural industry has the characteristics of compatibility and permeability. The connotation of cultural industry has penetrated into other industries, and compatible with them, such as automobile culture, home culture, corporate culture, food culture etc.. With the accelerated development of economy and culture, the relationship between economy and culture, culture and finance become more closely, the cultural industry production field and expanded space appear to be radioactive; also the development space of cultural industry becomes open.

- The cultural industry carries out the services through the creation of culture, the mining of cultural resources, the production of cultural products, and its core is to meet the spiritual needs of people. 


\section{The Characteristics of Cultural Industry Financing}

Compared with the traditional industries, the cultural industry's dependence on natural resources is relatively low, but the dependence on capital is relatively high. From the creation of a new cultural industry to a certain scale, it is necessary to invest a large amount of capital, so the capital scale is the main feature of cultural industry financing. On the other hand, the cultural industry is in a kind of innovative economic growth mode: the internal structure of the industry is dispersed, and the degree of intensification is low. The cultural industry chain is split obviously: first of all, the front end of the industrial chain is small and medium-sized enterprises which are weak and create original ideas; secondly, the middle of the industry chain is the cultural and creative production and publishing platform, but this part is controlled by major media organizations; finally, the final end of the industrial chain is cultural derivative link, and this part returns to the small and medium-sized manufacturing enterprises. Compared with the traditional industry's "a development, multiple use, superimposed on the profit" model, the cultural industry can not achieve this mode, resulting in a cautious attitude of most investment and financing institutions[10]. Furthermore, the modern culture industry is a modern entertainment formed with fashion and pop elements, which contain many uncertainties and many investors, are not willing to invest in the cultural industry based on this situation. In addition, the earnings lag in time, which increases the risk of capital. Based on the above considerations, the high risk of capital investment is another major feature of the cultural industry financing. The greater the risk is, the higher the expected return we get.

\section{ANALYSIS OF FINANCIAL SUPPORT MECHANISM FOR THE DEVELOPMENT OF CULTURAL INDUSTRY}

The capital of cultural industry mainly comes from three parts: the enterprises own accumulation, the government's financial support, and the financial market. Because the accumulation of the enterprise itself and the government's financial support are limited, so corporate finance mainly rely on the financial market. The financial market mainly consists of the money market represented by the commercial bank and the capital market represented by the securities company. The financial support for industrial development is mainly through the development of the two markets, which expand financial scale, improve financial structure, promote the efficiency of financial support, at the same time, play the function of financial market in accommodation, configuration, adjustment and reflection better, then improve the development of the industry, promote the upgrading of industrial structure, and stimulate economic growth.

In the discussion of the financial support mechanisms for the industrial development, we start with the characteristics of the development and the function finance played in the process of its development, mainly from the financial scale, financial structure and financial efficiency, to analyze how the financial market play function in the financial support, and systematically summarized the mechanism of industry development.

\section{A. Analysis on the mechanism of financial scale to promote the development of cultural industry}

To summarize the mechanism of financial scale to promote the development of cultural industry:

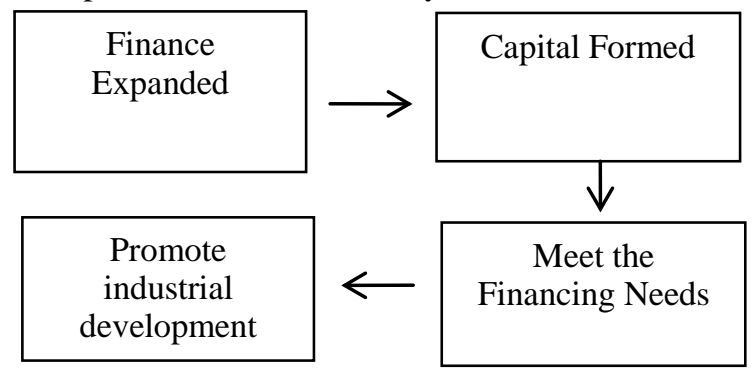

Fig. 1. The mechanism of financial scale to promote the development of industry

The cultural industry is a new industry, so the innovation and the advanced nature of culture decide that it needs massive capital investment to be strong and big. Enterprises are faced with the plight of the shortage of funds in the beginning and in the developing process. Enterprises' own accumulation of funds simply can not meet the needs of large-scale production and research, which formed a funding gap; however, the policy of financial support does not have the possibility of long-term funding, it's just a short guide, so enterprises can only rely on the support of the financial system to fill the funding gap, enabling enterprises to grow. The development of China's financial market is not very mature. The sources of corporate funds mainly rely on bank loans which are relatively single, and social capital sources have not formed a perfect import mechanism yet. According to a survey, the proportion of the current promising research which results into products or services in reality accounted for only $10 \%$, mainly because most projects can not get financial support in a timely manner[11]. Therefore, the expansion of the financial market can increase the supply of funds for the cultural industry to provide a number of financing guarantee, ease the financing pressure, and thus promote the rise of the cultural industry.

\section{B. Analysis on the Mechanism of Financial Structure to Promote the Development of Cultural Industry}

To summarize the mechanism of financial structure to promote the development of cultural industry:

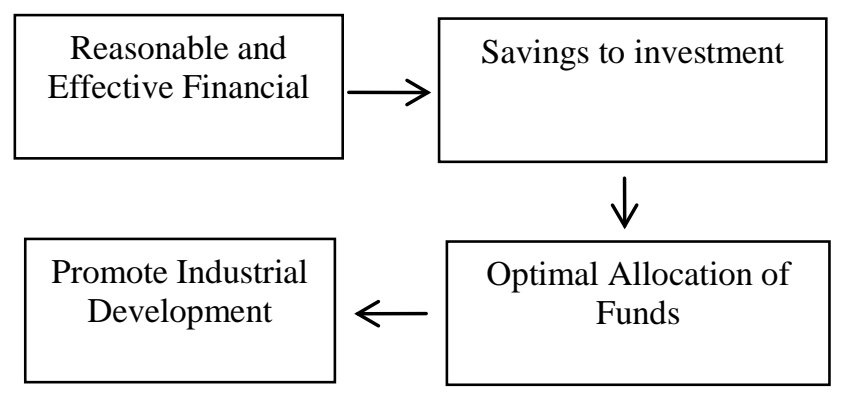

Fig. 2. The mechanism of financial structure to promote the development of industry

An optimized and reasonable financial structure should adapt to the economic structure and industrial development, 
meanwhile, each part can be fully and effectively connected and transmitted, and therefore it can play the function of the financial system and achieve a reasonable and effective financial structure. Different types of financial structure or different stages of development affect the efficiency and way of transforming savings into investment. Reasonable financial structure, can mobilize the active idle funds, improve the utilization rate, promote the investment funds; meanwhile, more active the fund is ,more frequent the investment activities is, more innovative financial products will appear to meet the various needs of investment. The effective circulation of information reduces the information asymmetry and moral hazard, and the fund holder is more willing to conduct investment behavior, thus solving the asymmetry between savers' long-term investments, financial surplus and diversification also promoting the speed of transforming savings into investment.

Therefore, efficient financial markets and optimized financial structure promote the improvement of the environment of financing, so that investors will turn the financial surplus into long-term capital, invest in high-yield long-term projects, at the same time, spread the risk of yield through the combination of assets, and improve investment return, then stimulate social investment in cultural industries [12].

\section{Analysis on the Mechanism of Financial Efficiency to Promote the Development of Cultural Industry}

To summarize the mechanism of financial efficiency to promote the development of cultural industry:

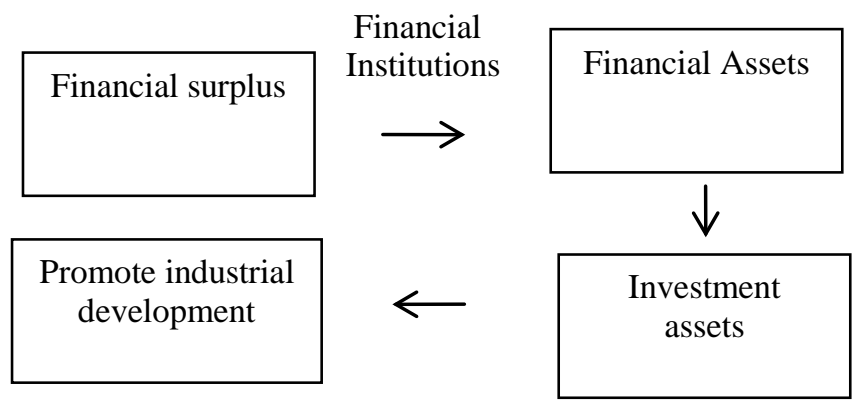

Fig. 3. The mechanism of financial efficiency to promote the development of industry

Financial efficiency refers to the efficiency of financial management, and also refers to the relationship between input and output of the financial sector. The financial scale and financial structure will not change in a short term, in order to achieve the optimal allocation of resources we need to achieve financial efficiency. Financial efficiency means the optimization of financial resources allocation. Financial institutions in the financial markets such as banks, securities companies, investment companies, absorb and gather the idle savings from the financial surplus holder by paying the cost, then transform them into financial capital and social disposable investment funds. In the end, the scale of financing will increase, the capital formation of the cultural industry will expand, and the optimal allocation of financial capital will be achieved. The more developed the financial market system is, the richer the main body of financial structure is, the higher the efficiency of transforming from savings into investment will be. Meanwhile, the financial efficiency can promote the improvement of the financial system and the optimization of the financial structure, thus forming a virtuous circle, which will create a good financial environment for the development of the cultural industry.

\section{CONCLUSIONS}

Capital is an important driving force for the development of cultural industries, and financial support is the core mechanism for this impetus to develop inner effect effectively. Under the optimal design of the capital allocation mechanism, financial supports provides sustained capital support for the development of the cultural industry, and promote the rapid development of the cultural industry, through the effective mobilization and capital agglomeration. In this progress, mobilization is the premise of the configuration, the configuration is the basis of efficiency, and efficiency is born in the configuration. Aimed at the enhancement of capital formation and the development of financial efficiency, based on the optimization of financial structure and the promotion of financial efficiency, the mechanism and path of financial support of cultural industry can be structured[13].

\section{ACKNOWLEDGMENT}

This work was financially supported by National Natural Science Foundation of China (71263011).

\section{REFERENCES}

[1] Goldsmith. Financial Structure and Financial Development.[M] Shanghai Sanlian Bookstore, Shanghai People's Publishing House, 1995.

[2] Wu Haihua, Zhang Xu. Economic Growth, Industrial Structure and Financial Development [J], Economic Theory and Economic Management, 2011.

[3] Cai Hongyan, Yan Qingmin. Industrial Structure Adjustment and Financial Development [J] Management World, 2004, (10).

[4] Zhou Zhengbing. Financial Support for Cultural Industries [J]. Invest Beijing, 2011, (10).

[5] Peng Zhongping, Nie Yong. Research on Financial Support for the Development of Cultural Industry in Guangxi [J]. Journal of Guangxi University For Nationalities (PHILOSOPHY AND SOCIAL SCIENCE EDITION), 2013, (7).

[6] Shi Weihua. Invest Cultural Industry; Highlight the Value of It [J]. Exploration and Free Views, 2007, (8).

[7] Liu Yuqing, He Shuhong. The Financial Support for the Development of Cultural Industry in Yunnan [J]. Inquiry into Economic Issues, 2014, (5).

[8] Wang Yang. China's Cultural Industry Development and Investment and Financing Support, Survey on the Situation of Shaanxi Cultural Industry[J] Chinese Cadres Tribune, 2014, (1).

[9] Classification of Cultural Industries Groups. Classification of Cultural Industries [S].2011-12.

[10] Lu Minfeng, Zhang Hui. Analysis of Financial Support System for the Development of Cultural Industry [J] West China Finance.2012 (4): 0204.

[11] Xie Xiaofeng. The research on Transformation form and path of scientific achievements in Colleges and Universities[J].Heilongjiang Researches on Higher Education.2012(04).

[12] $\mathrm{Xu}$ Jing. Study on financial structure of the United States [D]. Changchun: Jilin University, 2013.

[13] Xie Peishan. Financial Support Research on the Development of Hightech Industry in China and Japan [D]. Dalian: Dongbei University of Finance and Economics, 2010. 